\title{
SUDDEN CARDIAC ARREST IN A CASE WITH SEVERE ANAPHYLAXIS
}

\author{
Parminder Kaur, Roosy Aulakh, Samrat Hegde. \\ Department of Pediatrics, Government Medical College and Hospital, Chandigarh, India.
}

\section{KEYWORDS}

cardiac arrest, anaphylaxis , cardiopulmonary resuscitation

\section{ARTICLE HISTORY}

Received 11 December 2020

Accepted 5 February 2021
A 13-year-old male child presented with rash all over the body which was associated with intense itching. The rash developed following ingestion of oral cephalosporin which was prescribed to him by a private practitioner in view of fever for 2 days. On presentation, the general condition of child and vitals were stable except for the urticarial rash all over the body. As per the triage classification he was categorized as level 3 requiring urgent treatment. He was started on oral pheniramine $0.5 \mathrm{mg} / \mathrm{kg}$ and intravenous (IV) dexamethasone $0.15 \mathrm{mg} /$ $\mathrm{kg}$ to which symptoms resolved partially. Investigations showed hemoglobin of $13 \mathrm{gm} / \mathrm{dL}$, total leucocyte count 18,500 /cum (polymorphs 66\%, lymphocytes $30 \%$, eosinophils $2 \%$ ), platelet count $4,60,000 /$ cumm, serum sodium $142 \mathrm{meq} / \mathrm{l}$, serum potassium $5.2 \mathrm{meq} / \mathrm{l}$, blood urea $29 \mathrm{mg} / \mathrm{dl}$, serum creatinine $0.8 \mathrm{mg} / \mathrm{dl}, \mathrm{pH}$ of 7.4 with bicarbonate $21.1 \mathrm{mmol} / \mathrm{L}$, glucose $121 \mathrm{mg} /$ $\mathrm{dl}$, ionic calcium of $4 \mathrm{mg} / \mathrm{dl}$ (Normal: $4.8-5.52 \mathrm{mg} / \mathrm{dL}$ ) and normal urine examination. Previously, child had recurrent episodes of febrile urinary tract infection since one and half year of age but was not started on any prophylaxis. Ultrasound abdomen revealed right sided fullness of pelvicalyceal system with few internal echoes suggestive of pyelonephritis and irregular bladder wall with thickening suggestive of cystitis. After an initial improvement, there was sudden worsening six hours later in form of worsening rash, for which oral pheniramine $0.5 \mathrm{mg} / \mathrm{kg}$, and IV dexamethasone $0.15 \mathrm{mg} / \mathrm{kg}$ were repeated. He also developed difficulty in breathing for which injection adrenaline $0.3 \mathrm{ml}$ of 1 in 1000 dilution was given subcutaneously. However, child went into sudden cardiac arrest. Cardiopulmonary resuscitation was given, and child was intubated, and manual intermittent positive pressure ventilation was started. Electrocardiogram (ECG) showed asystole. Cardiac compressions were continued. Injection adrenaline $0.1 \mathrm{ml} / \mathrm{kg}$ of 1 in 10,000 dilution was given IV twice after which rhythm showed wide complex tachycardia suggestive of ventricular fibrillation for which defibrillation with 2 joules/kg was delivered and cardiac compressions were continued following which the rhythm changed to sinus rhythm and pulses were palpable. Cardiopulmonary resuscitation was continued for about half hour, following which child was shifted for post resuscitation care. IV adrenaline infusion at the rate of $0.1 \mathrm{mcg} / \mathrm{kg} / \mathrm{min}$ was started post

Address for Correspondance: Parminder Kaur, Department of Pediatrics, Government Medical College and Hospital, Chandigarh, India.

Email: kaurparminder1991@yahoo.in

@2021 Pediatric Oncall arrest. Few hours later child went into septic shock with wide pulse pressure. The focus of sepsis was attributed to pyelonephritis. After fluid resuscitation, IV noradrenaline infusion at the dose of $0.1 \mathrm{mcg} / \mathrm{kg} / \mathrm{min}$ was started and IV adrenaline infusion was stopped. Fresh frozen plasma was transfused in view of altered aspirates through nasogastric tube. Twelve hours post arrest, in view of good respiratory efforts, child was put on $T$ - piece ventilation and then extubated to nasal continuous positive airway pressure. He remained stable thereafter. In view of urinary tract infection and pyonephrosis, IV meropenem and vancomycin were started, and rest of the course remained uneventful. There was no neurological deficit.

Anaphylaxis is a severe form of allergic reaction, which may lead to life threatening circulatory failure and cardiac arrest. According to the various studies on anaphylaxis, the incidence of anaphylaxis in pediatric age group has been found to range from 10.5 to 70 episodes per 100000 person-years. ${ }^{1}$ In a case report on 34 cases of severe anaphylaxis in children seen in a pediatric allergy department, $61.8 \%$ of the cases analyzed were caused by drugs. ${ }^{2}$ As reported by Shalviri et al in their study, ceftriaxone was responsible for the highest number of deaths in their database (49 cases). Of 20,877 reports, $1205(5 \cdot 8 \%)$ were related to ceftriaxone; 357 reports (30\%) were categorized as serious including cardiac arrest, anaphylactic and anaphylactoid reactions. ${ }^{3}$ The most common systems involved in allergic reactions are respiratory (93\%), skin (93\%), cardiovascular (26\%) and neurologic (26\%). ${ }^{4}$ In our patient also, the child had severe anaphylactic reaction to cefixime. Hence, one should be cautious when prescribing cephalosporins and be aware of allergic reactions to the same.

\section{Compliance with Ethical Standards \\ Funding: None \\ Conflict of Interest: None}

\section{References:}

1. Bohlke K, Davis RL, DeStefano F, Marcy SM, Braun MM, Thompson RS. Epidemiology of anaphylaxis among children and adolescents enrolled in a health maintenance organization. J Allergy Clin Immunol. 2004; 113: 536- 542.

2. Topal E, Bakirtas A, Yilmaz O, Karagol IHE, Arga M, Demirsoy MS, et al. Severe anaphylaxis in children: a single-center experience. Pediatr Neonatol. 2014; 55: 320-322.

3. Shalviri G. Adverse events induced by ceftriaxone: a 10year review of reported cases to Iranian pharmacovigilance centre. J Clin Pharm Ther. 2012;37:448-451.

4. Dibs SD, Baker MD. Anaphylaxis in children: a 5-year experience. Pediatrics. 1997;99:E7. 